\title{
EHMTI-0198. Importance of neurovascular conflict with the trigeminal nerve in SUNCT and SUNA
}

\author{
G Lambru $^{1 *}$, P Shanahan ${ }^{2}$, I Davagnanam ${ }^{3}$, M Matharu $^{4}$ \\ From 4th European Headache and Migraine Trust International Congress: EHMTIC 2014 \\ Copenhagen, Denmark. 18-21 September 2014
}

\section{Introduction}

Recently, a small case series showed the presence of neurovascular conflict with the trigeminal nerve in a significant proportion of SUNCT and SUNA patients, suggesting a possible pathophysiological overlap between SUNCT, SUNA and trigeminal neuralgia (TN).

\section{Aims}

To assess the presence of a neurovascular conflict with the trigeminal nerve in a large series of SUNCT and SUNA patients.

\section{Methods}

Consecutive MRI examinations performed over the period from 2005 to 2013 from consecutive patients with SUNCT and SUNA syndromes were retrospectively reviewed by a consultant neuroradiologist blinded to the diagnosis and lateralisation of symptoms.

\section{Results}

The analysis included 89 patients (SUNCT $=45$ patients; SUNA $=44$ patients). Thirty SUNCT (66.7\%) and 29 SUNA patients $(65.9 \%)$ had a vascular loop ipsilateral to the side of the pain. Seven SUNCT (15.6\%) and three SUNA patients $(6.8 \%)$ showed a vascular loop contralateral to the side of the pain, whereas eight SUNCT (17.7\%) and 12 SUNA patients (27.3\%) showed no vascular loops. Of the 178 trigeminal nerves considered, a vascular loop was present in $59 / 95(62.1 \%)$ of the symptomatic trigeminal nerves, as opposed to $15 / 83(18.1 \%)$ of the asymptomatic nerves. There was a remarkable correspondence between the site of the pain $(\mathrm{V} 1, \mathrm{~V} 2, \mathrm{~V} 3)$ and the circumferential location of the site of vascular contact.

'Headache Group, UCL Institute of Neurology, London, UK

Full list of author information is available at the end of the article

\section{Conclusion}

The presence of neurovascular conflict with the trigeminal nerve in two-thirds of SUNCT and SUNA patients highlights their aetiological overlap with TN. The correlation between site of pain and location of the vascular contact supports the pathophysiological role of the compression of the trigeminal sensory root in SUNCT and SUNA.

No conflict of interest.

\section{Authors' details}

'Headache Group, UCL Institute of Neurology, London, UK. ${ }^{2}$ Headache Group, The National Hospital for Neurology and Neurosurgery, London, UK. ${ }^{3}$ Neuroradiology, The National Hospital for Neurology and Neurosurgery, London, UK. ${ }^{4}$ Headache Group, UCL Institute of Neurology and The National Hospital for Neurology and Neurosurgery, London, UK.

Published: 18 September 2014

doi:10.1186/1129-2377-15-S1-C35

Cite this article as: Lambru et al:: EHMTI-0198. Importance of neurovascular conflict with the trigeminal nerve in SUNCT and SUNA. The Journal of Headache and Pain 2014 15(Suppl 1):C35.

Submit your manuscript to a SpringerOpen ${ }^{\circ}$ journal and benefit from:

- Convenient online submission

- Rigorous peer review

- Immediate publication on acceptance

- Open access: articles freely available online

- High visibility within the field

- Retaining the copyright to your article

Submit your next manuscript at $\boldsymbol{~ s p r i n g e r o p e n . c o m ~}$

\section{SpringerOpen ${ }^{\circ}$}

(c) 2014 Lambru et al; licensee Springer. This is an Open Access article distributed under the terms of the Creative Commons Attribution License (http://creativecommons.org/licenses/by/2.0), which permits unrestricted use, distribution, and reproduction in any medium, provided the original work is properly cited. 